\title{
Comparative assessment of periodontal complex by experimental method and elaboration of new protocols for corresponding treatment of external and perforating internal resorption resulted many years after trauma.
}

\author{
Artak G Heboyan" ${ }^{*}$, Anna A Avetisyan² \\ ${ }^{1}$ Department of Prosthodontics, Yerevan State Medical University after M. Heratsi, Yerevan, Armenia \\ ${ }^{2}$ Department of Therapeutic Stomatology, Yerevan State Medical University after M. Heratsi, Yerevan, Armenia
}

\begin{abstract}
Objective The objective of the study is to assess the condition of periodontal complex by cone beam computed tomography and objective data of gingival crevicular fluid in young with different types of tooth root resorption as a result of a maxillofacial trauma, and to use the obtained results to develop new treatment strategy. Material and Methods This clinical, experimental, non-randomized study included cone beam computed tomography as well as determination of gingival crevicular fluid volume and $\mathrm{pH}$ in 4 patients who were divided in two groups. Both groups consisted of the patients with tooth root external and perforating internal resorption. In the first group (G1) antibiotics was administered along with conventional endodontic treatment, while in the second group (G2) endodontic treatment was carried out without antibiotics. Results in the G1 the volume of gingival crevicular fluid was $6 \mathbf{m m}^{2}$ and more, while $\mathrm{pH}$ was 6.5. No pain or edema were observed during the postoperative period. In the G2, the volume of gingival crevicular fluid was $6 \mathrm{~mm}^{2}$ and more, while $\mathrm{pH}$ was 7,0 and 6,5 in external and perforating internal resorption, respectively. Postoperative period was accompanied by pain, while edema was observed in perforating internal resorption. Conclusions According to the results obtained within the frames of this experimental study it can be concluded that the change in objective data of gingival crevicular fluid occurs in external and perforating internal root resorptions, while the use of antibiotics during the postoperative period prevents the occurrence of tenderness and complications such as edema.
\end{abstract}

Keywords: Periodontium, External resorption, Internal resorption, Gingival crevicular fluid, Root perforation. Accepted on June 21, 2019

\section{Introduction}

Tooth root resorption is yet not completely investigated, is often misdiagnosed and thus is not subjected to proper treatment. Root resorption is the destruction of cement and dentine conditioned by clastic cells activity [1,2]. In a healthy organism outer and inner walls of the tooth root are protected by the thin antiresorptive barrier. A layer of pre-cementum protects the outer wall meanwhile pre-dentine and odontoblasts protect the inner wall of root dentine. Clastic cells can't colonize non-mineralized surface [3]. A number of mechanical, chemical, thermal factors have been proved to cause premature mineralization of the protective barrier and stimulate resorptive process [4]. In this case, it becomes clear from the case history, that external and internal resorption in patients chosen for the study occurred as a result of trauma.

Resorption is defined as a condition associated with either physiological or pathological processes resulting in loss of dentine, cementum and bone. Tooth root resorption of permanent teeth is unfavorable phenomenon due to its pathologic character [5]. Tooth root resorption proceeds in three stages-initiation, resorption and repair [6]. The process of resorption can be self-limiting and clinically not manifested. If the resorptive process is sustained by infection, dental hard tissue destruction can lead to tooth loss.

There are different classifications of dental resorptive lesionshistological, etiological etc. [7,8]. The most widely spread is the classification based on the location of the resorptive lesion on the root surface, which then is sub-categorized according to pathogenesis, so there can be differentiated internal (inflammatory, replacement) and external (surface, inflammatory, replacement, cervical, transient apical breakdown) types. Both types more frequently occur in men than in women [9]. Only male patients were involved in the study which was initially conditioned by their attendance. Moreover, in this case the results and the conclusions of the research carried out among the patients of the same gender can be considered to be comparable and more reliable since the research is of an experimental character and doesn't include a large number of people. 
Clinical diagnosis of tooth root resorption is often made accidentally during X-ray examination. It is conditioned by the asymptomatic course of resorption until it gets to the stage of manifestation [10]. Discoloration of the crown with pink spot and gray shade is sometimes the only clinical manifestation, while other signs occur at the stage of complications. Thus, roentgenographic interpretation of resorption is crucial for differential diagnosis, treatment and outcome prognosis [11]. Regardless the X-ray film projection, internal resorption occurs in the X-ray image as symmetrical oval-shaped enlargement of root canal. In contrast, external resorption roentgenographically occurs in typical pathological lesion with rough, asymmetrical edges. In some cases, the lesion moves on parallax views, it looks like area separate from the root surface $[12,13]$. In patients who visited our clinic, tooth root external resorption was found accidentally during the X-ray examination, while patients with perforating internal resorption noted certain symptoms.

Traumatized teeth are clinical challenge from the point of view of the diagnosis, treatment planning and outcome prognosis. The newest achievements in X-ray image interpretation allow the doctor to effectively assess structural changes [14]. CBCT is highly important for the diagnosis and management of complicated endodontic cases [15-18]. Covering small field of view, CBCT allows for 3D high-resolution images of the teeth and adjacent dentoalveolar structures [19]. CBCT images assess resorptive process in submillimeter layers of different root areas, avoiding the overlay of anatomical structures [20]. This will ensure compliance with the ALARA 'as low as reasonably achievable' principle and achieve the lowest effective dose based on the number of teeth affected and sites involved. Clinicians should undergo appropriate training to have proper knowledge on $\mathrm{CBCT}$ before prescribing $\mathrm{CBCT}$ scans $[21,22]$. CBCT should be seen as supplement and not a replacement for conventional radiography. A CBCT should only be considered after the thorough clinical and conventional radiographic examination and assessment have been carried out.

The treatment of resorption varies, depending on its type, location, lesion size and clinical manifestations [23-25]. In the course of endodontic treatment antibiotics are used to combat infections and to prevent the complications and spread of the disease [26]. Antibiotics do not reduce the risks of the pain and edema in apical periodontitis. These are indicated only when there is systemic response of the organism or the patient suffers from any concomitant disease [27]. In case of trauma, antibiotics are prescribed when replantation of avulsed teeth is performed [28]. Endodontic intervention, carried out during this research, were performed according to standard protocol [29]. At the same time, the condition of periodontal complex was assessed by the objective studies of gingival crevicular fluid before and after the treatment. Based on the results obtained, administration of antibiotics was found to be necessary in external and perforating internal root resorptions.

In the literature we studied, no author had presented an assessment of the periodontal tissue condition in various types of tooth root resorptions by quantitative study and $\mathrm{pH}$ determination of gingival crevicular fluid. Similarly, no necessity in antibiotic administration was described in the treatment of traumatic external and internal perforating resorption when revealed years after trauma. Thus, the aim of the research is to study objective changes of gingival crevicular fluid data before and after the treatment in various types of tooth root resorption by experimental methods and to decide the expediency of antibiotic application in aforementioned pathologies.

\section{Materials and Methods}

To make the results of the study comparative, four patients of the same gender at the age of 20-25, with no accompanying severe somatic diseases on examination as well as in the past medical history, with no harmful habits (smoking, drug addiction, alcoholism) were chosen. All the patients were Armenians, born and grown in the same city. All of them had trauma of anterior teeth in their past medical history. All the patients presented with affected central incisors.

Cone beam computed tomography, determination of gingival crevicular fluid volume and $\mathrm{pH}$ were carried out within the study.

Taking into consideration the fact that changes of vestibule and oral root surfaces are not visible in the two-dimensional images due to shadow overlay, jaw scanning was performed by means of cone beam computed tomography (Planmeca ProMax 3D Max, Planmeca, Finland). The images were analyzed by Planmeca Romexis computer program (Planmeca, Finland).

The material for the gingival crevicular fluid volume determination was taken 3 hours after breakfast. The study area was isolated with cotton rolls and was dried off by weak air jet. Gingival crevicular fluid was collected by PERIOPAPER (Gingival crevicular fluid Collection Strips, Oralflow, Smithtown, NY 11787, USA) paper strip. The latter was thoroughly inserted into the gingival sulcus before reaching the slightest resistance and was left there for 30 seconds. Normally absorbent surface with gingival crevicular fluid is $0-5 \mathrm{~mm}^{2}$ [30].

In order to determine the $\mathrm{pH}$ of gingival crevicular fluid a special data "Plastic pH Data Strips" (Hydrion, USA) was used, which was into gingival sulcus. Gingival crevicular fluid $\mathrm{pH}$ can vary ranging from 6.30 to 7.93 [9].

Gingival crevicular fluid study was carried out after confirming diagnosis by CBCT. The total number of the patients was 4, who were divided in two groups. Each group included a patient with perforating root internal resorption and one with external root resorption. In the $\mathrm{G} 1$, along with endodontic treatment the patients were prescribed 2 pills of $1000 \mathrm{mg}$ amoxicillin orally on the first day, afterwards antibiotic therapy was carried out for four more days with $500 \mathrm{mg}$ amoxicillin pills taken 3 times a day. No antibiotics were prescribed within the course of endodontic treatment in the G2. The objective data of gingival 
Comparative assessment of periodontal complex by experimental method and elaboration of new protocols for corresponding treatment of external and perforating internal resorption resulted many years after trauma

crevicular fluid were determined again at the end of the treatment.

\section{Results}

The results of the study obtained in two groups were as presented in the Table 1.

Table 1. Gingival crevicular fluid volume and pH data in 4 patients before and after treatment as well as objective and subjective findings on patient examination in postoperative period.

\begin{tabular}{|c|c|c|c|c|c|c|}
\hline \multirow{2}{*}{ Groups } & \multirow{2}{*}{ Resorption type } & \multicolumn{2}{|c|}{ Gingival crevicular fluid volume $\left(\mathrm{mm}^{2}\right)$} & \multicolumn{2}{|c|}{ Gingival crevicular fluid $\mathrm{pH}$} & \multirow{2}{*}{$\begin{array}{l}\text { Objective and subjective data } \\
\text { on patient examination in } \\
\text { postoperative period }\end{array}$} \\
\hline & & Before treatment & After treatment & Before treatment & After treatment & \\
\hline \multirow{2}{*}{ G1 } & External & 6 & 3 & 6,5 & 7,0 & - \\
\hline & Perforating internal & 8 & 4 & 6,5 & 7,0 & - \\
\hline \multirow{2}{*}{ G2 } & External & 6 & 4 & 7,0 & 7,0 & Postoperative pain \\
\hline & Perforating internal & 7 & 5 & 6,5 & 6,5 & $\begin{array}{l}\text { Postoperative pain and slight } \\
\text { edema }\end{array}$ \\
\hline
\end{tabular}

In the $\mathrm{G} 1$, where the $\mathrm{pH}$ of the gingival crevicular fluid was 6,5 and the volume exceded the norm, constituting about $6 \mathrm{~mm}^{2}$ and more, the course of endodontic-antibiotic combined treatment went on smooth and uneventful, with no pain or edema during postoperative period. In the G2 where endodontic treatment was not combined with antibiotics, postoperative period was accompanied by pain, while edema was observed in perforating internal resorption. At the end of the treatment the change in the objective data of gingival crevicular fluid data as well as decrease in gingival crevicular fluid volume and $\mathrm{pH}$ increase were observed in the G1 and G2.

\section{Discussion}

In tooth root external and perforating internal resorption periodontium is also involved in the process, which is indicated by roentgenographic changes, gingival crevicular fluid volume increase and $\mathrm{pH}$ reduction. Peculiarity and significance of the study is the fact that the condition of periodontal complex in young people with different types of tooth root resorption, developed years after trauma was first assessed by experimental method by means of $\mathrm{CBCT}$ and gingival crevicular fluid study. Moreover, the data obtained have been used to work out a new treatment strategy, according to which the use of antibiotics in treatment of external and perforating internal resorption during the postoperative period was suggested in order to avoid unfavorable complications.

Though periapical roentgenograms are of initial significance in the diagnosis of endo-periodontal pathologies, the new X-ray extraoral imaging systems, which allow to assess the actual size, character, location of periapical and resorptive lesions more precisely are beneficial for the early diagnosis of different resorption types [9-22]. Regardless the data on antibiotic administration in literature, where they are indicated only in certain severe cases, this experimental study suggests to expand the indications for their administration to some extend in endodontic practice [26-28].

\section{Conclusion}

Within the scope and limitations of this study, the results obtained allow to conclude that the objective changes in gingival crevicular fluid data, peculiar for inflammation, such as increase in gingival crevicular fluid volume and acidic $\mathrm{pH}$, take place in external and perforating internal resorptions. It should be noted that positive change in gingival crevicular fluid data is observed regardless the use of antibiotics. Thus, in this case, antibiotic therapy is recommended along with endodontic treatment which can reduce the risk of undesirable side effects and complications such as pain and edema in the course of treatment.

\section{References}

1. Trope M. Root resorption due to dental trauma. Endod Topics 2002; 1: 79-100.

2. Patel S, Kanagasingam S, Ford PT. External cervical resorption: a review. J Endod 2009; 35: 616-625.

3. Al-Qawasmi RA, Hartsfield JK, Everett ET, Flury L, Liu L, Foroud TM, Macri JV, Roberts WE. Genetic predisposition to external apical root resorption in orthodontic patients: linkage of chromosome-18 marker. J Dent Res 2003; 82: 356-360.

4. Mincik J, Urban D, Timkova S. Clinical Management of Two Root Resorption Cases in Endodontic Practice. Case Rep Dent 2016; 9075363.

5. Patel S, Ford PT. Is the resorption external or internal? Dent Update 2007; 34: 218-229.

6. Mavridou AM, Hauben E, Wevers M, Schepers E, Bergmans L, Lambrechts P. Understanding external cervical resorption in vital teeth. J Endod 2016; 42: 1737-1751.

7. Patel S, Ricucci D, Durak C, Tay F. Internal root resorption: a review. J Endod 2010; 36: 1107-1121.

8. Heithersay GS. Management of tooth resorption. Aust Dent J 2007; 52: 105-121. 
9. Heboyan AG, Avetisyan AA, Margaryan MM. Clinical case of a rarely diagnosed tooth root internal resorption. Arme Med J 2018; 12: 87-92.

10. Nilsson E, Bonte E, Bayet F, Lasfargues JJ. Management of Internal Root Resorption on Permanent Teeth. Int J Dent 2013; 929486.

11. Heboyan AG, Avetisyan AA. The current concepts of the development mechanisms of the tooth root internal resorption. Issues in theoretical and clinical medicine, $\mathrm{J}$ of Sci Pract Med 2011; 14: 30-34.

12. Estrela C, Bueno MR, Alencar AH, Mattar R, Neto VJ, Azevedo BC, Estrela CR. Method to evaluate inflammatory root resorption by using cone beam computed tomography. J Endod 2009; 35: 1491-1497.

13. Patel S, Dawood A, Wilson R, Horner K, Mannocci F. The detection and management of root resorption lesions using intraoral radiography and cone beam computed tomography-an in vivo investigation. Int Endod J 2009; 42: 831-338.

14. Heboyan AG, Avetisyan AA, Margaryan MM, Azatyan VY. Rare clinical case of tooth root external resorption as a delayed post-traumatic complication. Arme Med J 2018; 12: 93-98.

15. Abella F, Patel S, Sindreu DF, Mercadé M, Bueno R, Roig M. An evaluation of the periapical status of teeth with necrotic pulps using periapical radiography and cone-beam computed tomography. Int Endod J 2014; 47: 387-396.

16. Brady E, Mannocci F, Brown J, Wilson R, Patel S. A comparison of cone beam computed tomography and periapical radiography for the detection of vertical root fractures in endodontically treated teeth. Int Endod J 2014; 47: 735-746.

17. Ee J, Fayad MI, Johnson BR. Comparison of endodontic diagnosis and treatment planning decisions using conebeam volumetric tomography versus periapical radiography. J Endod 2014; 40: 910-916.

18. Rodríguez G, Abella F, Sindreu DF, Patel S, Roig M. Influence of cone-beam computed tomography in clinical decision making among specialists. J Endod 2017; 43: 194-199.

19. European Society of Endodontology, Patel S1, Durack C, Abella F, Roig M, Shemesh H, Lambrechts P, Lemberg K. European Society of Endodontology position statement: the use of CBCT in endodontics. Int Endod J 2014; 47: 502-504.

20. Loubele M, Bogaerts R, Dijck VE, Pauwels R, Vanheusden S, Suetens P, Marchal G, Sanderink G, Jacobs R. Comparison between effective radiation dose of CBCT and MSCT scanners for dentomaxillofacial applications. Eur J Radiol 2009; 71: 461-468.
21. Horner K, Islam M, Flygare L, Tsiklakis K, Whaites E. Basic principles for use of dental cone beam computed tomography: consensus guidelines of the European Academy of Dental and Maxillofacial Radiology. Dentomaxillo fac Radiol 2009; 38: 187-195.

22. Brown J, Jacobs R, Jäghagen LE, Lindh C, Baksi G, Schulze D, Schulze R. Basic training requirements for the use of dental CBCT by dentists: a position paper prepared by the European academy of dentomaxillofacial radiology. Dentomaxillo fac Radiol 2014; 43: 20130291.

23. Elbay ÜŞ, Elbay M, Kaya E, Sinanoglu A. Management of an Intruded Tooth and Adjacent Tooth Showing External Resorption as a Late Complication of Dental Injury: ThreeYear Follow-Up. Case Rep Dent 2015; 2015: 741687.

24. Fernandes M, Ataide I, Wagle R. Tooth resorption part I pathogenesis and case series of internal resorption. J Conserv Dent 2013; 16: 4-8.

25. Elbay ÜŞ, Baysal A, Elbay M, Sarıdağ S. Multidisciplinary approach to delayed treatment of traumatic teeth injuries involving extrusive luxation, avulsion and crown fracture. Oper Dent 2014; 39: 566-571.

26. American Association of Endodontists, Guidance on the Use of Systemic Antibiotics in Endodontics, 2017.

27. Segura-Egea JJ, Gould K, Ǎžen BH Jonasson P4, Cotti E, Mazzoni A, Sunay H, TjÃaderhane L, Dummer PMH. Antibiotics in Endodontics: a review. Int Endod J 2017; 50: 1169-1184.

28. Andersson L, Andreasen JO, Day P, Heithersay G, Trope M, Diangelis AJ, Kenny DJ, Sigurdsson A, Bourguignon C, Flores MT, Hicks ML, Lenzi AR, Malmgren B, Moule AJ, Tsukiboshi M. International Association of Dental Traumatology guidelines for the management of traumatic dental injuries: 2. Avulsion of permanent teeth. Dent Traumatol 2012; 28: 88-96.

29. American Association of Endodontists, Treatment Standarts, 2018.

30. Guentsch A, Kramesberger M, Sroka A, Pfister W, Potempa J, Eick S. Comparison of Gingival Crevicular Fluid Sampling Methods in Patients with Severe Chronic Periodontitis, 2011; 82: 1051-1060.

\section{*Correspondence to:}

Artak G Heboyan

Department of Prosthodontics

Yerevan State Medical University after M. Heratsi

Yerevan

Armenia 